\title{
A TRADUÇÃO ENQUANTO PROCESSO
}

\author{
Renata Mancini ${ }^{1}$ \\ ${ }^{1}$ Universidade Federal Fluminense, Niterói, Rio de Janeiro, Brasil
}

\begin{abstract}
Resumo: Concebidos tradicionalmente em torno de dicotomias bem estabelecidas, os estudos sobre tradução acabam por deixar ainda amplo espaço à construção de um caminho teórico que trate a tradução enquanto processo, não apenas como elemento implícito à existência do produto, mas com uma proposta de conceitos dotados de valor operacional. Ao trazermos a Semiótica discursiva, mais especificamente os recentes desdobramentos da abordagem tensiva de Claude Zilberberg, para dialogar com as questões basilares dos Estudos de Tradução e de Adaptação, temos como ambição apresentar uma reflexão que se liberte da lógica binária das oposições para embarcar nas tensões inerentes aos regimes de dominância de uma lógica participativa. Nossa proposta culmina na afirmação de que o que se traduz é o projeto enunciativo, um "espírito" da obra de partida que molda suas características mais marcantes, do qual emana o que denominamos arco tensivo, um perfil sensível da obra, passível de ser modulado a partir do conjunto de estratégias de textualização de que o enunciador se vale, com suas cifras tensivas subjacentes. Procuramos mostrar que um caminho possível em direção ao interstício da oposição binária pode ser trilhado e aprofundado em várias frentes.

Palavras-chave: Tradução; Semiótica; Processo; Projeto Enunciativo; Arco Tensivo
\end{abstract}

\section{TRANSLATION AS A PROCESS}

\begin{abstract}
Traditionally conceived around well-established dichotomies, translation studies end up leaving ample room for the construction of a theoretical path that treats translation as a process, not only as an implicit element to the product's existence, but with a proposal of concepts endowed with operational value. By bringing discursive semiotics, more
\end{abstract}


specifically the recent developments in Claude Zilberberg's tensive approach, to dialogue with the fundamental issues of Translation and Adaptation Studies, we aim to present a reflection that breaks free from the binary logic of oppositions to embark on tensions inherent in the dominance regimes of a participatory logic. Our proposal culminates in the statement that what is translated is the enunciative project, a "spirit" of the original work that shapes its most striking characteristics, from which it emanates what we call the tensive arc, a sensitive profile of the work, which can be modulated from the set of textualization strategies that the enunciator uses taking into account their underneath tensive ciphers. We seek to show that a possible path toward the binary opposition interstice can be trod and deepened on several fronts.

Key-words: Translation; Semiotics; Process; Enunciative Project; Tensive Arc

\section{1) Da oposição à participação: o caminho}

Abandonar a lógica das oposições para embarcar no processo e entender a tradução a partir da tensão inerente ao entre-lugar da relação de obras, línguas, linguagens, culturas em diálogo é o desafio que abraçamos em nossa pesquisa e que discutiremos em linhas gerais neste artigo. Concebidos tradicionalmente em torno de dicotomias bem estabelecidas, os estudos sobre tradução acabam por deixar ainda amplo espaço à construção de um caminho teórico que trate a tradução enquanto processo, não apenas como elemento implícito à existência do produto, mas com uma proposta de conceitos dotados de valor operacional.

Tradução ao pé da letra ou do sentido geral, visibilidade ou invisibilidade do tradutor, fidelidade ou traição, transparência ou opacidade, tradutibilidade ou intradutibilidade, produto ou processo, as discussões que criam o universo conceitual da tradução parecem tirar da lógica da oposição a vitalidade de suas principais questões e dos encaminhamentos possíveis para suas soluções. Se muito já se avançou seguindo esse percurso, algo se deixou de ver em nome 
dessa escolha. Kamilla Elliot ${ }^{1}$ já nos chamava a atenção para o fato de que há muito a se buscar no interstício das oposições. O problema, segundo a autora, seria exatamente o de encontrar um caminho para que pudéssemos pensar as questões inerentes ao fazer tradutório fora da demarcação segura dos polos de uma oposição.

Ao trazermos a Semiótica discursiva, mais especificamente os recentes desdobramentos da abordagem tensiva de Claude Zilberberg, para dialogar com as questões basilares dos Estudos de Tradução e de Adaptação, temos como ambição apresentar uma reflexão que se liberte da lógica das oposições para embarcar nas tensões inerentes aos regimes de dominância de uma lógica participativa. Isso porque o arcabouço de sustentação dos estudos tensivos poderia ser resumido nos seguintes termos: as dependências tomam o lugar das oposições, a foria (uma força sensível) se estabelece como direcionadora dos processos de significação e o afeto passa a ser entendido como o valor do valor.

Nesse sentido, as dicotomias basilares passam a ser analisadas a partir da dinâmica de forças que se estabelece entre polos, neste caso, tomados como nada além de balizas nos extremos de um contínuo modulável. Assim, visibilidade e invisibilidade do tradutor, para tomarmos um exemplo, passam a ser oscilações possíveis de efeitos de sentido de uma presença complexa e, ao mesmo tempo, inequívoca. Fidelidade e traição passam a ser horizontes apenas teóricos de um escalonamento de relações em que identidades mais marcadas ou mais tênues, respectivamente, se desenham entre as obras de partida e de chegada.

Ao abandonarmos os lugares firmes de um extremo "ou" outro e nos abrirmos para a lógica participativa dos termos complexos, em que um polo "e" outro coexistem em tensão, em um jogo de forças que determina uma dinâmica fluida de dominâncias de um sobre o outro, não precisamos, necessariamente, optar por analisar a tradução como produto "ou" processo. Afinal, é processo "e"

Em palestra intitulada "Adaptation and theorization", apresentada em 17/11/2017, na II Jornada de Tradução e Adaptação - FFLCH/USP.

Cad. Trad., Florianópolis, v. 40, n 3, p. 14-33, set-dez, 2020. 
produto ao mesmo tempo e procuraremos mostrar como a interface com a semiótica tensiva permite que essa posição complexa se desprenda de um horizonte teórico para ganhar valor operacional.

O diálogo com a semiótica em sua vertente tensiva forja também um caminho concreto de aproximação entre os Estudos de Tradução e os Estudos de Adaptação. Erigida a partir da noção de que a interface sensível rege os caminhos de processamento inteligível do texto (texto não apenas verbal, mas entendido no seu sentido semiótico amplo, como qualquer articulação de um conteúdo e sua expressão) e baseada em noções abstratas e dinâmicas, a abordagem tensiva permite a construção de uma malha de conceitos comuns tanto às questões de tradução interlingual como de adaptação, que aqui passaremos entender como tradução intersemiótica. Que fique claro que de modo algum estamos propondo um esmaecimento das diferenças entre as duas áreas de saber e dos problemas inerentes às suas especificidades. Estamos apenas escolhendo investir naquilo que ambas possam ter em comum, a despeito de suas particularidades que em nada perdem em importância.

Iniciamos nossa proposta afirmando que o que se traduz é o projeto enunciativo, esse "espírito" da obra de partida que molda suas características mais marcantes. Dele faz parte o que denominamos arco tensivo, um perfil sensível da obra, passível de ser modulado a partir do conjunto de estratégias de textualização de que o enunciador se vale, com suas cifras tensivas subjacentes. Trataremos dos detalhes dessa formulação adiante.

Reconstruir o projeto enunciativo de partida sob as novas coerções impostas pela concepção da obra de chegada (coerções que podem ser de diversas ordens, como diferenças semânticas e sintáticas de uma nova língua, mobilizações sensoriais diversas em linguagens diferentes, nova cultura, perfil do leitor etc.) faz com que o tradutor se coloque na posição de um Janus que deve tirar da sua interpretação da obra de partida as escolhas que darão forma à obra de chegada.

Ao tomarmos essa posição estamos, por um lado, de acordo com Arrojo (1986) quando diz que: 
Nossa tradução de qualquer texto, poético ou não, será fiel não ao texto "original", mas àquilo que consideramos ser o texto original, aquilo que consideramos constituí-lo, ou seja, à nossa interpretação do texto de partida, que será, como já dissemos, sempre produto daquilo que somos, sentimos e pensamos (Arrojo 44).

No entanto, ao mesmo tempo, fazemos coro com Eco quando admite que o texto já impõe coerções e caminhos de leitura:

traduzir quer dizer entender o sistema interno de uma língua e a estrutura de um texto dado naquela língua, e construir um duplo do sistema textual que, sob uma certa descrição, possa produzir efeitos análogos no leitor, seja no plano semântico e sintático, seja no plano estilístico, métrico, fonossimbólico, seja quanto aos efeitos passionais para os quais o texto fonte tendia ${ }^{2}$. (Eco (a) 16)

Estabelecemos os caminhos metodológicos para dotar nossa proposta de valor operacional exatamente na tensão entre o fazer interpretativo do tradutor como leitor da obra de partida, que fará as devidas triagens, as escolhas dos elementos que compõem o projeto enunciativo original, e que integrarão o fazer persuasivo implicado em seu projeto de tradução como criador da obra de chegada, na esteira de Ricoeur (2011) quando indaga:

Como faz um tradutor? Emprego propositalmente o verbo 'fazer'. Pois é com um 'fazer', à procura de sua teoria,

${ }^{2}$ [...] tradurre vuole dire capire il sistema interno di una lingua e la struttura di un testo dato in quella lingua, e costruire un doppio del sistema testuale che, sotto una certa descrizione, possa produrre effetti analoghi nel lettore, sia sul piano semantico e sintattico che su quello stilistico, metrico, fonossimbolico, e quanto agli effetti passionali a cui il testo fonte tedeva (tradução de Cecília Maculan Adum). 
que o tradutor ultrapassa o obstáculo - e mesmo a objeção teórica - da intraduzibilidade de princípio de uma língua a outra. (Ricoeur 62)

A tensão entre dois fazeres, o interpretativo e o persuasivo, irmanados no papel do tradutor, é a força que estabelece a relação entre os projetos enunciativos de partida e de chegada; é a ponte para nos posicionarmos no entre-lugar movediço (e escorregadio) do processo.

\section{2) O fazer tradutório: um fazer complexo}

A posição de pivô do tradutor, cujo fazer interpretativo da obra de partida guia as estratégias de textualização de que se valerá para recriar no texto de chegada o fazer persuasivo responsável pela adesão do novo leitor, faz com que o fazer tradutório seja, em si, um termo complexo que congrega e complexifica duas modalidades do fazer: o fazer interpretativo e o fazer persuasivo.

Desde as primeiras formulações da teoria semiótica, essa relação entre os fazeres é contemplada: "É na qualidade de atividade semiótica que a tradução pode ser decomposta em um fazer interpretativo do texto a quo, de um lado, e em um fazer produtor do texto ad quem, de outro" (Greimas \& Courtés 509). O que procuramos enfatizar aqui é o fato de que ambos se coadunam em um mesmo actante: o tradutor.

O papel do tradutor se constitui, portanto, entre esses dois fazeres que tensionados estabelecem o fluxo de criação que, se por um lado, mantém a autonomia do ato enunciativo, por outro, determina a operação das escolhas que o tradutor faz dos elementos do texto de partida a serem recriados sob novas coerções. Nesse sentido, endossamos o que Britto (1999) aponta como diferenças "qualitativas" do ato de criação do autor da obra original e da obra traduzida, não obstante entendamos que não nos parece que haja uma criação propriamente diferente, mas sim um jogo de forças de 
contenção maior que guiam o ato criador, isto é, o ato enunciativo, relativo ao fazer do tradutor na construção de seu texto, na medida em que não se pode negar o diálogo direto da obra traduzida com a obra original a ser, em maior ou menor grau, recriada sob novas coerções. O que resta é que o percurso de criação do tradutor, mesmo que conte com guias mais definidas, não deixa de ser um ato de enunciação, um ato de criação, portanto. Como nos lembra Otavio Paz (2009), "cada tradução é, até certo ponto, uma invenção e assim constitui um texto único" (Paz 13).

Haroldo de Campos (b), no paralelismo que traça entre Valéry e Benjamin, aponta que:

Também para Benjamin, é a um 'tônus emocional' que a 'significação poética' da palavra no original responde, para além da mera reprodução do sentido; não visa ao significado enquanto tal, mas à vinculação deste com o 'modo de significar', com uma forma significante, portanto, que estrutura o intencionar do poema original para a 'língua pura'. Se o poeta (espécie singular da categoria geral dos 'tradutores', para Valéry) busca ideias 'para suas palavras e ritmos predominantes' (este seria o seu 'trabalho interno', ou, como eu gostaria de dizer, a sua operação de codificação intersemiótica), o tradutor benjaminiano de poesia - o 'transpoetizador' - está liberado dessa 'busca de ideias' pelo próprio poema original (que já as pré-constituiu, e nisso presta um serviço à tarefa da tradução, permitindo-lhe concentrar-se na desvelação do referido código intersemiótico, ou seja: no 'modo de intencionar', de 'significar', de 'formar' ínsito a esse original) (Campos (b) 67).

Na formulação semiótica, a invisibilidade do tradutor não existe per se, já que o estatuto de sujeito da enunciação do tradutor jamais pode ser desprezado. Para Greimas e Courtés (2008), “o termo sujeito da enunciação, empregado frequentemente como sinônimo de enunciador, cobre de fato as duas posições actanciais de 
enunciador e enunciatário" (Greimas \& Courtés 171). Ao congregar no mesmo sujeito as posições de quem concebe a obra e de para quem ela é concebida, a semiótica atrela o ato de leitura à própria construção da significação.

Invisibilidade e visibilidade do tradutor nada mais são, sob essa ótica, do que efeitos de presença mais explicita ou mais escondida desse sujeito que ao enunciar pode, pelas estratégias de como se projeta no enunciado, deixar suas marcas vivas e sua subjetividade plenamente à mostra, como também pode encobrir suas pegadas para criar efeito de distanciamento, isenção ou objetividade. O importante é nunca perder de vista que, em qualquer dos casos, trata-se da escolha do enunciador (o tradutor aqui), de uma estratégia para impulsionar seu fazer persuasivo em relação ao novo perfil de leitor (enunciatário) do texto traduzido. O tradutor, portanto, mesmo quando escolhe se "esconder" no modo como enuncia, nunca é invisível. Mesmo que por vias diferentes, a formulação semiótica abona a visão de Lawrence Venuti (1995), entre outros, para quem tradutor e criador devem inequivocamente gozar de status equivalente.

\section{3) O que se traduz: o projeto enunciativo e seu arco tensivo}

Fazendo coro com Valéry (1955), para quem "escrever, o que quer que seja, desde o momento em que o ato de escrever exige reflexão [...] é um trabalho de tradução (Valery apud Campos 61), Greimas e Courtés (2008) apresentam no Dicionário de Semiótica a noção de traduzibilidade de maneira ampla: "entre o juízo existencial 'há sentido' e a possibilidade de dizer alguma coisa a seu respeito intercala-se, com efeito, a tradução: 'falar de sentido' é ao mesmo tempo traduzir e produzir significação" (Greimas \& Courtés 508). Tomada a partir desse horizonte amplo, qualquer atividade de construção de sentido é uma tradução e, portanto, se enquadra como "uma propriedade fundamental dos sistemas semióticos" (ibidem). Essa concepção englobante instiga o tratamen- 
to semiótico também no que tange aos problemas específicos do fazer tradutório. A memorável formulação de Haroldo de Campos abre vias substanciais para a reflexão semiótica:

A tradução de textos criativos será sempre recriação, ou criação paralela, autônoma porém recíproca. Quanto mais inçado de dificuldades esse texto, mais recriável, mais sedutor enquanto possibilidade aberta de recriação. Numa tradução dessa natureza, não se traduz apenas o significado, traduz-se o próprio signo [...] (Campos (a) 35).

A inseparabilidade entre o modo de manifestação e o significado manifestado de que se vale a semiótica francesa, assentada na função semiótica que articula, necessariamente, um plano de expressão ${ }^{3}$ e um plano de conteúdo, está em completa sintonia com a ideia de que se deve traduzir o signo em sua totalidade. A visada semiótica prevê que se leve em conta, no processo de tradução, a significação enquanto produto da articulação de um conteúdo com a interface sensível (expressão) que o manifesta. Podemos, assim, aquiescer ao pedido estranhamente ainda válido de Susan Sontag (2013), feito nos idos anos 60, para que se dê mais atenção à "forma" nos objetos artísticos a fim de evitarmos o que ela entende ser uma arrogância da interpretação quando o peso do conteúdo é exacerbado.

Interpretação toma como ponto passivo a experiência sensível da obra de arte e parte daí. Mas ela não pode mais ser tomada como ponto passivo. [...] O importante agora é recuperarmos nossos sentidos. Precisamos aprender a ver mais, a ouvir mais, a sentir mais" ${ }^{4}$ (Sontag 17 - tradução nossa).

${ }^{3} \mathrm{O}$ plano de expressão equivale ao que algumas abordagens denominam forma.

${ }^{4}$ Interpretation takes the sensory experience of the work of art for granted, and proceeds from there. This cannot be taken for granted, now [...] What is important now is to recover our senses. We must learn to see more, to hear more, to feel more (SONTAG 17). 
A importância da "forma" (tomada aqui como plano de expressão), que articulada ao conteúdo estabelece a função semiótica (correlato hjelmsleviano do signo saussuriano) é inequívoca, embora, do ponto de vista operacional nos estudos de tradução, os planos nem sempre se apresentem de modo intimamente irmanados. De todo modo, Haroldo de Campos, uma das vozes brasileiras mais influentes na teorização do fazer tradutório, diz que em Paul Valéry:

a fidelidade ('sensibilidade') às formas convoca uma 'força cantante', capaz de orquestrar a seleção combinatória dos 'recursos latentes' que o poeta entesoura em sua organização falante [...] essa 'força cantante' que faz com que 'a semelhança fonológica' seja sentida como um 'parentesco semântico', as estruturas gramaticais sejam subliminarmente pressentidas como uma partitura de paralelismo e contrastes (Campos (b) 63).

Tratando da transposição criativa de Jackbson, Campos ainda diz que:

o procedimento do poeta-tradutor (ou tradutor-poeta) seria o seguinte: descobrir (desocultar), por uma 'operação metalinguística' voltada sobre o plano formal (da expressão ou do conteúdo) qual o código de 'formas significantes' de que o poema representa a mensagem ou realização ad hoc [...] em seguida reequacionar os constituintes assim identificados, de acordo com critérios de relevância estabelecidos in caso, e regidos, em princípio, por um isomorfismo icônico, que produz o mesmo sob a espécie da diferença na língua do tradutor (Campos (b) 93).

O que nos interessa aqui é exatamente investir na operação metalinguística que congregue as formas (de expressão e conteúdo) de modo a dar relevo às "formas significantes", de que fala Campos, 
que integram e revelam o próprio corpo do poema. É no esforço de Claude Zilberberg em "gramaticalizar" os afetos a partir de categorias básicas e abstratas como andamento e tonicidade que enxergamos uma via de acesso a elas.

Luiz Tatit (2019), apresenta Claude Zilberberg como sendo o

semioticista que trouxe a música, a intensidade, a temporalidade e os afetos para o centro da teoria, num diálogo permanente com os fundamentos estruturais [e que] empenhou-se em construir uma 'prosodização do conteúdo', atividade que pode ser resumida no contraponto da semiotização fundada por Algirdas Julien Greimas com a temporalização praticada por Paul Valéry, com a ideia de acentuação adotada por Ernest Cassirer e ainda a musicalização encontrada em Gisèle Brelet. (Tatit 16)

Ao analisar em minúcias o projeto de prosodização do conteúdo de Zilberberg, Tatit vislumbra uma "prosodização epistemológica" (ibidem) que prevê movimentos de ida (ascensão) para o acento principal e volta (descida) para o repouso (inacento), responsáveis por uma direção geral de construção do sentido. Seria como um traço suprassegmental da expressão a ser usado para entender o plano do conteúdo, numa retomada decidida da noção do isomorfismo entre os planos, segundo a qual o acento no plano de expressão corresponderia a uma ênfase no plano do conteúdo. Ao embarcarmos no modelo zilberberguiano, "compreender o texto é entender a acentuação do texto", como nos sugere Luiz Tatit (2019) ${ }^{5}$ no limite de um esforço de abstração.

O que está em jogo, no fundo, é a possibilidade de o funcionamento prosódico das línguas naturais com seus acentos e modulações, ascendentes e descendentes, oferecer um

${ }^{5}$ Formulação apresentada em palestra ministrada no XVIII mini-ENAPOL de Semiótica, em 10/10/2019, na FFLCH/USP. 
modelo eficaz para se compreender também os aumentos e diminuições típicos das apreciações que realizamos do sentido abstrato. (Tatit 16)

O caminho que forjou a possibilidade de uma prosodização do conteúdo foi a noção de timia, "disposição afetiva fundamental" (Greimas \& Courtès 505), que se abre para a dimensão afetiva inerente e implicada em qualquer manifestação do sentido. Embora aqui não caiba um desdobramento mais detalhado da proposta tensiva, vale destacar que foi com o propósito de gramaticalizar a dimensão dos afetos que Zilberberg (a) constrói seu edifício teórico. O "timismo seria estruturalmente prosódico e se manifestaria tanto sob a forma de acentuação quanto da modulação" (Zilberberg apud Tatit 92).

Ao acolher uma dimensão sensível no bojo da teoria, Zilberberg (b) instaura uma subjetividade que ordena o mundo a partir do ponto de vista de um sujeito (da enunciação) que impõe sua presença tanto pela dimensão sensível (passional e sensorial) quanto inteligível da construção do sentido. Por meio da subjetividade implicada no ato de enunciar (que congrega o ponto de vista que concebe e aquele que interpreta o texto), a abordagem tensiva ordena o sentido na articulação de uma intensidade sensível que rege uma extensidade inteligível. É a força de ordenação da intensidade regente que serve de base para a adoção, nos dois planos (expressão e conteúdo), de critérios prosódicos ( $c f$. Tatit 92).

Tomando por base a proposta tensiva, à tradicional pergunta "o que, afinal, se traduz?", que engloba todas as questões cruciais dos estudos de tradução e adaptação, temos uma resposta direta: o projeto enunciativo e o arco tensivo que dele emana.

O arco tensivo é o desenho da interface sensível de uma obra, um perfil que se constrói a partir da alternância entre momentos de impacto (mais fortes ou mais tênues) e momentos brandos (em graus de atonia), isto é, entre saliências (acentos) e "passâncias" (inacentos), que se alternam em ascendências e descendências de maior ou menor grau. Depreendido a partir das cifras tensivas dos 
elementos que constituem o projeto enunciativo, nossa proposta é a de que o arco tensivo seja uma baliza primordial do fazer tradutório. Para esclarecer nosso argumento, vejamos como pensar teoricamente a descrição do arco tensivo em sua relação íntima com o projeto enunciativo, tratado em algum detalhamento.

\subsection{Do projeto enunciativo ao arco tensivo}

Entendemos por projeto enunciativo o conjunto de estratégias de textualização postas em prática no ato de criação que dão corpo ao projeto de persuasão de um enunciador (o perfil discursivo de quem "diz") em relação ao fazer interpretativo do perfil específico de enunciatário visado (perfil discursivo do leitor, espectador, ouvinte etc.). Vale reforçar que o fazer interpretativo aqui contempla também os modos de engajamento sensível, para além dos elementos de construção da inteligibilidade.

No coração dessa questão reside uma dinâmica de gestão de expectativas, tomadas enquanto caminhos de leitura previstos pelas estratégias postas em prática pelo enunciador, em função dos caminhos interpretativos do enunciatário. Essa dinâmica de manutenção e/ou de quebra de expectativas é explicada por Zilberberg (b) por meio das lógicas implicativa - em que há a manutenção da expectativa para o desfecho de um caminho proposto - ou a lógica concessiva, em que há a quebra da expectativa inicialmente construída.

A construção de acentos pode se dar, por exemplo, com a exacerbação de elementos passionais, com o jogo de imprevistos que causam susto ou estranhamento no leitor, com a construção de suspense. São várias as estratégias das quais o enunciador pode se valer para criar saliências sensíveis (em variados graus de tonicidade) a serem recriadas, ou pelo menos levadas em conta, nas escolhas de um tradutor. Pautando-se, primordialmente, por recriar o perfil sensível da obra de partida sob novas coerções,

[o] tradutor, por assim dizer, 'desbabeliza' o stratum semiótico das línguas interiorizadas nos poemas, procedendo 
como se (ficção heurística, verificável casuisticamente na prática experimental) esse 'intracódigo' fosse intencional ou tendencialmente comum ao original e ao texto resultante da tradução; texto que o tradutor constrói paralelamente (paramorficamente) ao original, depois de 'desconstrui-lo' num primeiro momento metalinguístico. (Campos 101)

Em sintonia com a proposta de Campos (b), quando indica que para chegarmos a esse "stratum semiótico" desbabelizante do sensível, comum a qualquer língua ou linguagem, há que se passar pela etapa de desconstrução metalinguística, retornamos à noção do projeto enunciativo, que nada mais é do que uma análise do texto segundo categorias semióticas para que, a partir de suas potencialidades de uso, sejam depreendidas cifras tensivas às quais se atribui um valor de acento ou inacento.

Definimos o projeto enunciativo como um conjunto de estratégias postas em prática pelo sujeito da enunciação para orquestrar as categorias semióticas em um todo de sentido. Mas como caracterizar o projeto enunciativo da obra de partida? Se partíssemos das características específicas do plano de conteúdo das línguas e linguagens envolvidas, procederíamos à desconstrução metalinguística com critérios semióticos organizados segundo três eixos principais:

- 1) Foco narrativo: diz respeito à hierarquia dos programas narrativos que estabelece um peso diferenciado a cada uma das narrativas que organizam o conteúdo do texto, assim como seus modos de disposição - teia, em paralelo, de modo sequencial etc.

- 2) Dinâmica das perspectivas (ou pontos de vista): o jogo de vozes e os tipos de organização temporal e espacial, isto é, o modo como o enunciador se vale dos elementos da sintaxe discursiva para estabelecer suas estratégias de persuasão.

- 3) Direcionamento ideológico/axiológico: as escolhas semânticas, temáticas e figurativas, definem uma chave axiológica que pode ser mantida ou subvertida de uma obra para a outra. 
$\mathrm{Na}$ sequência, a questão é entender como a estratégia de disposição das categorias organizadas nesses três eixos pode criar acentos ou "passâncias", momentos tônicos ou átonos, em suma, como depreender suas cifras tensivas para que cheguemos no arco tensivo da obra.

Já dissemos que tudo é uma questão de gestão da expectativa prevista pelo enunciador em relação ao fazer interpretativo do enunciatário. Em Grande Sertão: veredas, de Guimarães Rosa, por exemplo, embora tudo indicasse que Diadorin fosse um homem (era jagunço etc.), na verdade, era uma mulher e o momento dessa descoberta por Riobaldo é o acento mais tônico da obra (ápice), que jamais poderia ser negligenciado em um projeto tradutório (interlingual ou intersemiótico) que visasse manter alguma identidade entre as obras. O que permite a existência dessa força concessiva (impacto) é a dinâmica das perspectivas, que se assenta em um jogo de vozes, no qual o narrador e o personagem Riobaldo aparecem sincretizados (sobrepostos) em alguns momentos, fazendo com que tenhamos o ponto de vista da vivência (não da observação) dos fatos na narração. ${ }^{6}$

Não nos seria possível, nos limites desse artigo, discutir os exemplos em detalhes. No entanto, em termos gerais, podemos dizer que uma obra que proponha uma teia narrativa intrincada, com muitos programas narrativos, sem que a ligação entre eles se estabeleça de maneira clara, é um exemplo de acento. O embaralhamento de vozes do narrador e personagem (como no discurso indireto livre ou em outras estratégias de apagamento ou quebra da hierarquia de vozes, como mencionamos acima) são exemplos de aceleração do conteúdo e consequente, construção de uma saliência, de um momento tônico.

O mesmo acontece com a construção de isotopias díspares (linhas temático-figurativas distantes ou sem conexão aparente entre

6 Para uma discussão mais detalhada ver Mancini, Renata. "Os modos de engajamento do leitor de Grande sertão: veredas em quadrinhos”. Todas as Letras, São Paulo, v. 21, n. 1, p. 100-113, jan./abr. 2019. 
elas, como no caso do poema "Carnaval", do álbum Nome, de Arnaldo Antunes (1993): “árvore/pode ser chamada de/pássaro/pode ser chamado de/máquina/pode ser chamada de/carnaval/carnaval/ carnaval".

A disrupcão de um caminho temático-figurativo previsível, ou o uso de um desencadeador de isotopia (elemento que quando aparece inaugura um novo campo semântico a partir do qual os elementos já dispostos passam a ganhar nova leitura), recurso muito utilizado em piadas, são alguns exemplos possíveis dos modos de dispor o conteúdo de forma acelerada e tônica, na medida em que todas essas estratégias, narrativas ou discursivas, criam a necessidade de um engajamento maior do enunciatário para que o sentido final do texto se construa.

Entendemos esse engajamento maior do enunciatário como uma maior demanda por catálises prevista pelo enunciador a partir das estratégias de textualização postas em prática. Lembremos que para Greimas e Courtès (2008), “catálise é a explicitação dos elementos elípticos ausentes na estrutura de superfície" (Greimas \& Courtés 54).

Um texto que preveja elementos elípticos em sua superfície, ou seja, que apresente "lacunas" de sentido a serem preenchidas pelo enunciatário, demanda catálise. As "lacunas" podem ser de diferentes ordens - narrativas (como em um romance em que apenas o início e o final da narrativa são mostrados, deixando para o leitor inferir o meio, ou mesmo os filmes que terminam sem deixar claro o final da narrativa) ou discursivas (um jogo de vozes complexo, disposição temporal dos fatos não linear etc.). Quanto maior a demanda por catálise, mais exacerbado o engajamento sensível do enunciatário.

É importante frisar que fica a critério do enunciador deixar lacunas mais abertas ou mais fechadas, a serem preenchidas de maneira mais livre ou mais "guiada”, por assim dizer. Quanto mais aberta, mais impactante, quanto mais fechada, menos. Há também que se levar em consideração que em uma obra que prevê um perfil amplo de enunciatário, muitas são as possibilidades de interação com o texto. No entanto, como nos alerta Eco: 
Um texto 'aberto' continua, ainda assim, sendo um texto, e um texto pode suscitar uma infinidade de leituras sem, contudo, permitir uma leitura qualquer. [...] Mas um texto é um organismo, um sistema de relações internas que atualiza certas ligações possíveis e narcotiza outras.(Eco (b) 81)

Essas ligações "narcotizadas" pelo enunciador no texto são aquelas que demandam a intervenção ativa do leitor. Um conteúdo apresentado de modo abrupto ou acelerado ao enunciatário cria a necessidade de uma leitura que, partindo de certa indeterminação criada pela aceleração, vá aos poucos desacelerando o conteúdo, o que é o mesmo que dizer que vá explicitando os elos inicialmente apresentados como lacunas de sentido.

No outro extremo, um arranjo narrativo claro, com todos os elos mostrados, isotopias temático-figurativas costuradas de maneira explícita, vozes, tempos e espaços bem delimitados, definidos e estáveis são escolhas que desaceleram o conteúdo e não demandam tanto engajamento do enunciatário, na medida em que todos os passos do desenvolvimento sintagmático do texto estão dados, o que define um modo de engajamento sensível modulado pelo conforto que cria na interface sensível da obra um inacento.

Em suma, tudo aquilo que se apresenta subitamente, provocando estranheza, comoção, surpresa, susto, enquanto quebra de expectativa, cria acentos, se oferece pela intensidade, por um andamento acelerado, constrói saliências perceptivas (acentos) nos momentos de impacto. Apenas quando o sujeito consegue desacelerar o conteúdo de alguma maneira (preenchendo as lacunas, entendendo as costuras invisíveis) é que a demarcação inteligível vai, mais e mais, tomando forma. No outro extremo, tudo que é apresentado como previsivelmente encadeado, fazendo sentido o tempo todo, reverberando as construções do imaginário social sedimentados na práxis, constrói-se pelo estilo implicativo, pelo andamento desacelerado, o que cria na interface sensível da obra o inacento.

Foge também aos limites desse artigo pensar as cifras tensivas dos elementos de expressão (ou forma) que constituem as obras a 
serem analisadas em seu processo tradutório. No entanto, vale ressaltar que a mesma metalinguagem tensiva pode ser aplicada para elementos de quaisquer planos de expressão (verbal, visual, musical, gestual, sincrético etc.), deixando claro o valor heurístico da proposta de se oferecer como metalinguagem comum a diferentes ordens sensoriais e a diferentes linguagens.

É claro que, por diferentes razões, o projeto tradutório pode ter como objetivo a construção de uma identidade mais forte entre as obras de partida e chegada, assim como pode também prever um distanciamento, criando, até certo ponto, uma impressão de autonomia entre elas. O simulacro de proximidade, ou efeito de fidelidade, pode ser pensado como uma interface translúcida, em que é possível enxergar, em maior ou menor grau, uma obra na outra, apesar da opacidade inerente às suas diferenças. O que está em jogo é a recriação de um projeto enunciativo em outro. Algumas estratégias mostram mais a identidade entre as obras que outras. De todo modo, a noção de fidelidade, pensada a partir de um escalonamento de identidades, pode variar no continuum entre forte e tênue, também desafiando o binarismo no qual se assenta. Essa seria uma discussão em si que não caberia aqui. O que importa é mostrar que um caminho possível em direção ao interstício da oposição binária pode ser trilhado e aprofundado em várias frentes.

\section{Referências}

Arrojo, Rosemery. Oficina de tradução - A teoria na prática. São Paulo: Atica, 1986.

Britto, Paulo Henriques. Tradução e criação. Cadernos de Tradução, v.1, n.4, p.239-262, 1999. Disponível em: https://periodicos.ufsc.br/index.php/traducao/ article/view/5534/4992. Acesso em: 15/12/2019.

Cad. Trad., Florianópolis, v. 40, no 3, p. 14-33, set-dez, 2020. 
Campos, Haroldo de (a). Metalinguagens e outras metas. São Paulo: Perspectiva, 2006.

Campos, Haroldo de (b). Transcriação. Marcelo Tápia e Thelma Médici Nóbrega (orgs.). São Paulo: Perspectiva, 2015.

Eco, Umberto (a). Dire quasi la stessa cosa. Milão: Bompiani, 2010.

Eco, Umberto (b). Os limites da interpretação. Tradução de Pérola de Carvalho. São Paulo: Perspectiva, 2012.

Greimas, Algirdas Julien; Courtés, Joseph. Dicionário de Semiótica. Tradução de Alceu Dias Lima et al. São Paulo: Contexto, 2008.

Paz, Octavio. Tradução: literatura e literalidade. Ed. Bilíngue. Tradução de Doralice Alves de Queiroz. Belo Horizonte: FALE/UFMG, 2009.

Ricouer, P. Sobre tradução. Tradução de Patrícia Lavelle. Belo Horizonte: Editora UFMG, 2011.

Sontag, Susan. Against interpretation and other essays. New York: Picador, 2013.

Tatit, Luiz. Passos da Semiótica Tensiva. São Paulo: Ateliê Editorial, 2019.

Valery, Paul. Variations sur les Bucoliques. Traduction en vers des Bucoliques de Virgile. Paris: NRF, 1955.

Venuti, Lawrence. The translator's invisibility: A history of translation. Routledge: London, 1995.

Zilberberg, Claude (a). "Défense et illustration de l'intensité". In: Fontanille, Jacques (org.). La quantité et ses modulations qualitatives. Limoges, Amsterdam e Philadelphia: PULIM e Benjamins, 1992. 
Zilberberg, Claude (b). Elementos de Semiótica Tensiva. Tradução de Ivã Carlos Lopes, Luiz Tatit, Waldir Beividas. São Paulo: Ateliê Editorial, 2011.

Recebido em: 09/03/2020

Aceito em: 22/05/2020

Publicado em setembro de 2020

Renata Mancini. E-mail: renata.mancini@gmail.com. ORCID: https://orcid. org/0000-0001-9813-6157. 